\title{
Evaluating the Final Outcomes for Treatment Given in Cases of Lumbar Prolapsed Intervertebral Disc and Factors Affecting the Outcomes. Result from Dr. Hardas Singh Orthopedic Hospital and Superspeciality Research Centre, Circular Road, Amritsar, Punjab
}

Dr. Pancham Prasad*, Dr. Parvinder Singh Sandhu

HOD, Department of Orthopedic Dr. Hardas Singh Orthopedic Hospital and Superspeciality Research Centre, Circular Road, Amritsar, Punjab, India

DOI: $10.36347 / \mathrm{sajb} .2020 . \mathrm{v08i11.002}$

| Received: 01.11.2020 | Accepted: 08.11.2020 | Published: 13.11 .2020

*Corresponding author: Dr. Pancham Prasad

Abstract

Original Research Article

Background: Most common source of lower back pain is degeneration of intervertebral space leading to degenerative disc disease and lumbar herniation. We have various practices in India that include bending and twisting of the spine, making up for a strong case to study in detail about various causes of lumbar disc disease in patients coming to a tertiary center for treatment. Material and method: A hospital based study was conducted after clearance from IEC Dr. Hardas Singh orthopedic hospital and superspeciality research centre in from Jan 2019 till Feb 2020. Data were collected on structured questionnaire according to the set inclusion criterion for willing and consenting patients. Results: In our study we had 58 participants having more than $85 \%$ males with mean age of 23.45 . Most of the patients were treated conservatively with excellent results. Conclusion: More large sample size is needed to come at any conclusion while like other published results we too saw that in most cases with age conservative management is a successful approach. Keywords: lower back pain, lumbar disc disease, patients, Treatment.

Copyright ( 12020 The Author(s): This is an open-access article distributed under the terms of the Creative Commons Attribution 4.0 International License (CC BY-NC 4.0) which permits unrestricted use, distribution, and reproduction in any medium for non-commercial use provided the original author and source are credited.

\section{INTRODUCTION}

Herniation of the lumbar disc in young and middle-aged patients is a common disease that often affects the spine and causes lower back pain. Data in the USA estimates an annual loss exceeding USD 100 Billion in the US only [1].

There are various reasons for the chronic lower back pain which often is presented in the OPDs of orthopedics department late after onset, as acute low back pains are rarely of other origin than of trauma [2].

Most common source of lower back pain is degeneration of intervertebral space leading to degenerative disc disease and lumbar herniation. A complex structure composed of collagen, proteoglycans and sparse fibrochondrocytic cells is the lumbar intervertebral disc which serves to dissipate forces on the spine. The disc fibrochondrocytes can experience senescence as part of normal aging process and proteoglycan production decreases $[3,4]$.

This results in a lack of hydration and a collapse of the disc, which increases the tension on the annulus fibrous fibers around the disc. Annulus tears and cracks can result, making a herniation of the disc material easier, if adequate forces are placed on the disc. Alternatively, a strong biomechanical force put on a normal disc may lead to the extrusion of disc material when the annular fibers are seriously damaged $[5,6]$.

Herniations often mean protrusion of disc material through the spinal canal and beyond the limits of the annular lining, all resulting in back pain [7].

We have various practices in India that include bending and twisting of the spine. Some of them are religious postures, floor seating for eating food, squatting in an Indian toilet, and washing the floors. For these factors, there is a risk in the Indian population of more asymptomatic disc degeneration and herniation compared to that of the West. Unfortunately, the literature does not include any Indian details. MRI reveals both physiological and pathological changes that can mislead a less skilled health professional and may also have a poor mental effect on an otherwise stable person $[8,9]$. 
Before the age of 20, LDD can occur, but it peaks in the fourth and fifth decades of life and subsequent declines. Often it results in physical disability, It needs surgery and results in failure to work and inability to work. It has an economic effect on the community through significant losses. Its exact prevalence, is not very clear, but maybe best estimates are as per Finninsh - Health survey which puts men to be $5.1 \%$ of total Finnish population while $3.7 \%$ female age over 30 years. While evidences from other populations had projected prevalence close to $1-40 \%[10,11]$.

Lumbar disc degeneration and herniation are typically linked primarily to age, gender, body mass index (BMI), smoking, physical activity, and heavy spinal loading. However recent evidences have pointed out about genetic predisposition and point that various genetic sequences are associated with disease [12].

Given the paucity of clear evidences regarding the aetiologies patient education is an important approach so that they come at an early stage. Also various treatment modalities like steroid injections at local site in epidural region or surgical treatment and conservative managements like moderate nonsteroidal anti-inflammatory, such as ibuprofen $800 \mathrm{mg}$ every eight hours as needed, or tramadol $50 \mathrm{mg}$ every 4-6 hours as needed, form the main stay of available modalities in Indian setup [13].

Though the treatment listed above is accepted and universally practiced, evidence regarding the benefits it gives to patients in Dr. Hardas Singh orthopedic hospital is not documented and present on various research data bases, With an aim to record the results of the open carpal tunnel release in patients, willing to participate in the study, this was planned, with these objectives:

1. To know the demography of the attending patients with complaints

2. To ascertain the functional outcome after the various treatment given in patients of lumbar disc disease.

\section{MATERIAL AND METHODS}

After the IEC clearance the study was planned. All willing patients participating were asked for informed consent .The study was starting Jan 2019 till Feb 2020 all patients visiting the OPD of Department of Orthopedics were asked to participate if they had lower back pain and diagnosis was lumbar disc disease. They were evaluated for various comorbid conditions. A semi structured questionnaire was used to document the various answers for questions based to achieve the objectives and included questions exploring the history of back pain, leg pain and claudication, leg paraesthesia and lower limb muscle weakness.
Some patients who presented with the lower back pain but were other wise not having any other problems were further evaluated using the questionnaire to label them as asymptomatic . The asymptomatic subject was described as one with a negative response to the questionnaire and has never seen a doctor, physiotherapist, chiropractor, acupuncture, traditional herbal medicine (ayurveda), or any other health care professional, and has never missed a working day due to low back ache and related symptoms in the past.

Included were all patients in the 18 to 50 -year age range with lumbar intervertebral disc prolapse, clinical signs and symptoms, and radiological confirmation. While patients with Structural scoliosis, Spondylolysthesis, Congenital anomalies, Developmental dysplasia, Infections of spine specific or nonspecific, Cauda Equina syndrome, Failed back syndrome, Disc herniations at multiple levels and Tumors of lumbar spine were categorically excluded.

The various treatment processes followed were -

a) Conservative management - For patients with radiation of pain or neurological symptoms or gross simple $\mathrm{x}$-ray anomalies, associated with back ache we employed conservative management .Rest on the injured spine, complete relief from weight bearing, analgesics and reassurance were the essence of conservative management . Usually we gave it for 6 weeks to 2 months.

b) Epidural Steroid Injection - This modality was used based on patient requirement and his willingness to accept this treatment wherein he or she was willing to take it for short term relief of his or her pain knowing fully well that the pain may come back and the relief will be short term. For symptomatic treatment of disco-genic back pain, the epidural injection of a combination of long-acting steroid methyl-prednisolone acetate (Depo-Medrol) [dose varied from 80 to $120 \mathrm{mg}$ with epidural anaesthesia $\{1 \%$ lidocaine $\}$ was administered.

c) Surgical Procedure - The ideal patient was one that had at least 6 weeks with predominant (if not just) unilateral leg pain extending below the knee. The discomfort were minimised by rest, anti-inflammatory medications, or even epidural steroids, but have returned to initial levels after at least 6 to 8 weeks of conservative treatment. In such cases we gave the option of surgical treatment .After general anesthesia was induced, patient were put prone over spinal frame (Relton and Hall frame). Extending down into the subcutaneous tissue, lumbodorsal fascia, and supraspinous ligament a midline skin incision was given over the spinous process centering the affected disc level. Subperiosteal dissection was done, separating 
the muscles from the spine and vertebrae laminae from distal to proximal on the side of the processes of the spines. Excision of the spinous process of the affected vertebrae. With the aid of kerrison rongeur, ligamentum flavum was removed from a rent made in the midline. The shelving portion of ligamentum flavum was carefully removed before exposed of dura, shielding the dura portion of the excised piecemeal lamina so that the nerve root is visible. The herniated disc was brought into view as the nerve root was placed medium-wise with the aid of dural retractors. An incision was made over the longitudinal ligament posterior and fibrosus annulus. Nucleus pulposus removed piecemeal with disc forceps. Following complete haemostasis with suction drain in situ, the wound was closed in layers.

\section{Postoperative follow up}

Generally patients after operation were given ample rest, antibiotics and mild stretching exercises were encouraged after 4-6 day once the pain was minimal while removal of sutures was done $14^{\text {th }}$ day on wards. Anti-inflammatory approaches were also effective adjuncts for patients routinely evaluated at 6 weeks, 3rd month and 6th month, and were promoted in particular for graded exercise programmes.

\section{The Evaluation Tools}

We used two most commonly used scales to report the patient reported outcome measures in spinal problems to evaluate the pain and functionality. 1) Visual Analogue Scale and 2) Oswerty Disbaility Index (ODI Score). The VAS is a unidimensional measure of pain intensity that is widely used for a range of conditions. The ODI, on the other hand, is a condition-specific measure for the assessment of outcomes in spinal pathologies. In VAS scores of 1-10 on a visible scale was given with 10 has having the worst possible pain while upto score of two meant mild, annoying pain. While in ODI scoring 10 sections had 6 questions and adding up the points obtained on the answers were divided by 50 and multiplied by 100 to get a $\%$ of disability. Once the $\%$ was obtained it was evaluated as 0 percent to 20 percent: marginal disability,
21 percent to $40 \%$ : Mild impairment, 41 to $60 \%$ : Serious impairment, 61 percent to 80 percent: Crippled, 81 to 100 percent: these patients are either bed-bound or their symptoms are exaggerated. Greater than $80 \%$ improvement and return to same work was considered to be having an excellent outcome.

\section{DATA ANALYSIS}

Data was inserted into Excel sheets, and using SPSS version 21 software, statistical analysis of the data was carried out. The mean \pm standard deviation was recorded as continuous data. Categorical data were reported as numbers and percentages and were analyzed using, as necessary, the Chi-square test or the exact Fisher test. The $\mathrm{P}<0.05$ value was considered statistically significant.

\section{RESULTS}

In our study we had 58 participants in which 54 males were there obviously more than females and average age was 23.42 , standard deviation was 4.51 with an age ranging 18-34 years. Majority of the occupation of participating patients were farmers followed by office job followed by individuals who basically worked as home helpers.

We had VAS and ODI scores on similar scales on day at admission and mostly were on the higher side of the scales meaning the patients were having pain of higher intensity and were having limited functionality.

On applying tests of association in form of chi square we had gender associated with occupation, age group and the association was of high statistical significance (Table-1). Similar association with gender and site involved in terms of lumbar segments and sacral segments and treatment offered was explored, both the associations were of high statistical significance (Table-2). Mostly patients were managed with conservative management followed by surgical treatment. Few takers were there for steroid injections. We noted tremendous increment in VAS scores and ODI scores Percentage improvement in all treatment modalities (Table $3 \& 4$ ). Surgical management was discectomy as per the described process. 
Table-1: Association of gender with other variables like SES, Occupation, Residence and other variables

\begin{tabular}{|c|c|c|c|c|c|}
\hline & \multicolumn{2}{|c|}{ Gender } & \multirow[t]{2}{*}{ Total } & \multirow[t]{2}{*}{ p value } \\
\hline & & Male & Female & & \\
\hline \multirow[t]{8}{*}{ Age in years } & \multirow[t]{2}{*}{$18.0-20.00$} & 21 & 1 & 22 & \multirow[t]{8}{*}{0.04} \\
\hline & & $36.2 \%$ & $1.7 \%$ & $37.9 \%$ & \\
\hline & \multirow[t]{2}{*}{ 20.1-25.0 } & 15 & 1 & 16 & \\
\hline & & $25.9 \%$ & $1.7 \%$ & $27.6 \%$ & \\
\hline & \multirow[t]{2}{*}{ 25.1.-30.0 } & 10 & 2 & 12 & \\
\hline & & $17.2 \%$ & $3.4 \%$ & $20.7 \%$ & \\
\hline & \multirow[t]{2}{*}{$>30$} & 8 & $\mathbf{0}$ & 8 & \\
\hline & & $13.8 \%$ & $0.0 \%$ & $13.8 \%$ & \\
\hline \multirow[t]{8}{*}{ Religion } & \multirow[t]{2}{*}{ Hindu } & 23 & $\mathbf{0}$ & 23 & \multirow[t]{8}{*}{0.54} \\
\hline & & $39.7 \%$ & $0.0 \%$ & $39.7 \%$ & \\
\hline & \multirow[t]{2}{*}{ Muslim } & 20 & 4 & 24 & \\
\hline & & $34.5 \%$ & $6.9 \%$ & $41.4 \%$ & \\
\hline & \multirow[t]{2}{*}{ Christian } & 7 & 0 & 7 & \\
\hline & & $12.1 \%$ & $0.0 \%$ & $12.1 \%$ & \\
\hline & \multirow[t]{2}{*}{ Others } & 4 & $\mathbf{0}$ & 4 & \\
\hline & & $6.9 \%$ & $0.0 \%$ & $6.9 \%$ & \\
\hline \multirow[t]{12}{*}{ Occupation } & \multirow[t]{2}{*}{ Sportsperson } & 4 & 0 & 4 & \multirow[t]{12}{*}{0.001} \\
\hline & & $6.9 \%$ & $0.0 \%$ & $6.9 \%$ & \\
\hline & \multirow[t]{2}{*}{ Farmer } & 16 & 0 & 16 & \\
\hline & & $27.6 \%$ & $0.0 \%$ & $27.6 \%$ & \\
\hline & \multirow[t]{2}{*}{ Home maker } & 6 & 4 & 10 & \\
\hline & & $10.3 \%$ & $6.9 \%$ & $17.2 \%$ & \\
\hline & \multirow[t]{2}{*}{ Labour } & 5 & 0 & 5 & \\
\hline & & $8.6 \%$ & $0.0 \%$ & $8.6 \%$ & \\
\hline & \multirow[t]{2}{*}{ Domestic Help } & 7 & 0 & 7 & \\
\hline & & $12.1 \%$ & $0.0 \%$ & $12.1 \%$ & \\
\hline & \multirow[t]{2}{*}{ Office Job } & 16 & 0 & 16 & \\
\hline & & $27.6 \%$ & $0.0 \%$ & $27.6 \%$ & \\
\hline \multirow[t]{4}{*}{ SES } & \multirow[t]{2}{*}{ APL } & 36 & 3 & 39 & \multirow[t]{4}{*}{0.67} \\
\hline & & $62.1 \%$ & $5.2 \%$ & $67.2 \%$ & \\
\hline & BPL & 18 & 1 & 19 & \\
\hline & & $31.0 \%$ & $1.7 \%$ & $32.8 \%$ & \\
\hline Residence & Urban & 20 & 2 & 22 & 0.45 \\
\hline & & $34.5 \%$ & $3.4 \%$ & $37.9 \%$ & \\
\hline & Rural & 34 & 2 & 36 & \\
\hline & & $58.6 \%$ & $3.4 \%$ & $62.1 \%$ & \\
\hline Total & & 54 & 4 & 58 & \\
\hline & & $93.1 \%$ & $6.9 \%$ & $100.0 \%$ & \\
\hline
\end{tabular}

Table-2: Association between gender and various treatment modalities

\begin{tabular}{|c|c|c|c|c|c|}
\hline & \multicolumn{2}{|c|}{ Gender } & \multirow[t]{2}{*}{ Total } & \multirow[t]{2}{*}{$p$ value } \\
\hline & & Male & Female & & \\
\hline \multirow[t]{6}{*}{ Site Involved } & \multirow[t]{2}{*}{ L2-L3 } & 3 & $\mathbf{0}$ & 3 & \multirow[t]{6}{*}{0.003} \\
\hline & & $5.2 \%$ & $0.0 \%$ & $5.2 \%$ & \\
\hline & \multirow[t]{2}{*}{ L2-L3,L3-L4,L4-L5 } & 1 & 0 & 1 & \\
\hline & & $1.7 \%$ & $0.0 \%$ & $1.7 \%$ & \\
\hline & \multirow[t]{2}{*}{ L2-L3,L3-L4 } & 50 & 4 & 54 & \\
\hline & & $86.2 \%$ & $6.9 \%$ & $93.1 \%$ & \\
\hline \multirow[t]{6}{*}{ Treatment Given } & \multirow[t]{2}{*}{ Conservative } & 42 & 3 & 45 & \multirow[t]{6}{*}{0.02} \\
\hline & & $72.4 \%$ & $5.2 \%$ & $77.6 \%$ & \\
\hline & \multirow[t]{2}{*}{ Epidural Injection } & 3 & 1 & 4 & \\
\hline & & $5.2 \%$ & $1.7 \%$ & $6.9 \%$ & \\
\hline & \multirow[t]{2}{*}{ Surgical Treatment } & 9 & $\mathbf{0}$ & 9 & \\
\hline & & $15.5 \%$ & $0.0 \%$ & $15.5 \%$ & \\
\hline \multirow{2}{*}{\multicolumn{2}{|c|}{ Total }} & 54 & 4 & 58 & \\
\hline & & $93.1 \%$ & $6.9 \%$ & $100.0 \%$ & \\
\hline
\end{tabular}


Pancham Prasad \& Parvinder Singh Sandhu., Sch Acad J Biosci, Nov, 2020; 8(11): 350-355

Table-3: Association between treatment given and Visual Analogue Scale scores on various days of treatment given followed up to 6 months

\begin{tabular}{|c|c|c|c|c|c|c|}
\hline & \multicolumn{3}{|c|}{ Treatment Given } & \multirow[t]{2}{*}{ Total } & \multirow[t]{2}{*}{ p value } \\
\hline & & Conservative & Epidural Injection & Surgical Treatment & & \\
\hline \multirow{8}{*}{$\begin{array}{l}\text { VAS on Day } 15 \text { post } \\
\text { T/T }\end{array}$} & \multirow[t]{2}{*}{ VAS 0-2 } & 2 & $\mathbf{0}$ & 0 & 2 & \multirow[t]{8}{*}{0.004} \\
\hline & & $3.4 \%$ & $0.0 \%$ & $0.0 \%$ & $3.4 \%$ & \\
\hline & \multirow[t]{2}{*}{ VAS 3-5 } & 42 & 1 & $\mathbf{0}$ & 43 & \\
\hline & & $72.4 \%$ & $1.7 \%$ & $0.0 \%$ & $74.1 \%$ & \\
\hline & \multirow[t]{2}{*}{ VAS6-7 } & 1 & 3 & 3 & 7 & \\
\hline & & $1.7 \%$ & $5.2 \%$ & $5.2 \%$ & $12.1 \%$ & \\
\hline & \multirow{2}{*}{ VAS 8-9 } & $\mathbf{0}$ & $\mathbf{0}$ & 6 & 6 & \\
\hline & & $0.0 \%$ & $0.0 \%$ & $10.3 \%$ & $10.3 \%$ & \\
\hline \multirow[t]{4}{*}{ VAS Post T/T day 30} & \multirow[t]{2}{*}{ VAS 0-2 } & 12 & 2 & 2 & 16 & \multirow[t]{4}{*}{0.002} \\
\hline & & $20.7 \%$ & $3.4 \%$ & $3.4 \%$ & $27.6 \%$ & \\
\hline & \multirow[t]{2}{*}{ VAS 3-5 } & 33 & 2 & 7 & 42 & \\
\hline & & $56.9 \%$ & $3.4 \%$ & $12.1 \%$ & $72.4 \%$ & \\
\hline \multirow{4}{*}{$\begin{array}{l}\text { VAS Post T/T } 3 \\
\text { Month }\end{array}$} & \multirow[t]{2}{*}{ VAS 0-2 } & 24 & 4 & 9 & 37 & \multirow[t]{4}{*}{0.002} \\
\hline & & $41.4 \%$ & $6.9 \%$ & $15.5 \%$ & $63.8 \%$ & \\
\hline & \multirow[t]{2}{*}{ VAS 3-5 } & 21 & $\mathbf{0}$ & $\mathbf{0}$ & 21 & \\
\hline & & $36.2 \%$ & $0.0 \%$ & $0.0 \%$ & $36.2 \%$ & \\
\hline \multirow{2}{*}{$\begin{array}{l}\text { VAS Post T/T } 6 \\
\text { Month } \\
\end{array}$} & \multirow[t]{2}{*}{ VAS 0-2 } & 45 & 4 & 9 & 58 & \multirow[t]{2}{*}{ NA } \\
\hline & & $77.6 \%$ & $6.9 \%$ & $15.5 \%$ & $100.0 \%$ & \\
\hline \multirow{2}{*}{\multicolumn{2}{|c|}{ Total }} & 45 & 4 & 9 & 58 & \\
\hline & & $77.6 \%$ & $6.9 \%$ & $15.5 \%$ & $100.0 \%$ & \\
\hline
\end{tabular}

Table-4: Association between treatment given and ODI scores on various days of treatment given followed up to 6 months

\begin{tabular}{|c|c|c|c|c|c|c|}
\hline & \multicolumn{3}{|c|}{ Treatment Given } & \multirow[t]{2}{*}{ Total } & \multirow{2}{*}{$\begin{array}{l}\mathbf{p} \\
\text { value }\end{array}$} \\
\hline & & Conservative & $\begin{array}{l}\text { Epidural } \\
\text { Injection }\end{array}$ & $\begin{array}{l}\text { Surgical } \\
\text { Treatment }\end{array}$ & & \\
\hline \multirow{8}{*}{$\begin{array}{l}\text { ODI Score on Day } 15 \\
\text { Post T/T }\end{array}$} & \multirow[t]{2}{*}{$0-20 \%$} & 1 & 1 & 0 & 2 & \multirow[t]{8}{*}{0.004} \\
\hline & & $3.4 \%$ & $1.0 \%$ & $0.0 \%$ & $3.4 \%$ & \\
\hline & \multirow[t]{2}{*}{$21-40 \%$} & 42 & 1 & $\mathbf{0}$ & 43 & \\
\hline & & $72.4 \%$ & $1.7 \%$ & $0.0 \%$ & $74.1 \%$ & \\
\hline & \multirow[t]{2}{*}{$41-60 \%$} & 1 & 3 & 3 & 7 & \\
\hline & & $1.7 \%$ & $5.2 \%$ & $5.2 \%$ & $12.1 \%$ & \\
\hline & \multirow[t]{2}{*}{$61-80 \%$} & $\mathbf{0}$ & $\mathbf{0}$ & 6 & 6 & \\
\hline & & $0.0 \%$ & $0.0 \%$ & $10.3 \%$ & $10.3 \%$ & \\
\hline \multirow{4}{*}{$\begin{array}{l}\text { ODI score Post T/T } 30 \\
\text { days }\end{array}$} & \multirow[t]{2}{*}{$0-20 \%$} & 12 & 2 & 2 & 16 & \multirow[t]{4}{*}{0.002} \\
\hline & & $20.7 \%$ & $3.4 \%$ & $3.4 \%$ & $27.6 \%$ & \\
\hline & \multirow[t]{2}{*}{$21-40 \%$} & 33 & 3 & 7 & 42 & \\
\hline & & $56.9 \%$ & $3.4 \%$ & $12.1 \%$ & $72.4 \%$ & \\
\hline \multirow{4}{*}{$\begin{array}{l}\text { ODI score Post T/T } 3 \\
\text { Month }\end{array}$} & \multirow[t]{2}{*}{$0-20 \%$} & 24 & 4 & 9 & 37 & \multirow[t]{4}{*}{0.002} \\
\hline & & $41.4 \%$ & $6.9 \%$ & $15.5 \%$ & $63.8 \%$ & \\
\hline & \multirow[t]{2}{*}{$21-40 \%$} & 21 & 0 & $\mathbf{0}$ & 21 & \\
\hline & & $36.2 \%$ & $0.0 \%$ & $0.0 \%$ & $36.2 \%$ & \\
\hline \multirow{2}{*}{$\begin{array}{l}\text { ODI score Post T/T } 6 \\
\text { Month }\end{array}$} & $0-20 \%$ & 45 & 4 & 9 & 58 & \multirow[t]{2}{*}{ NA } \\
\hline & & $77.6 \%$ & $6.9 \%$ & $15.5 \%$ & $100.0 \%$ & \\
\hline \multirow{2}{*}{\multicolumn{2}{|c|}{ Total }} & 45 & 4 & 9 & 58 & \\
\hline & & $77.6 \%$ & $6.9 \%$ & $15.5 \%$ & $100.0 \%$ & \\
\hline
\end{tabular}

\section{DISCUSSION}

Most lumbar prolapsed intervertebral disc cases respond to the conservative management line. Therefore, except for large discs without cauda equine, it is safe to follow wait and watch policies. Short-term outcome of discectomy for PIVD is favorable relative to conservative at the end of six months, but the outcome of surgical management is still better than conservative management in Weber et al. studies and sport trial 2006 12 at 4 years, while statistical significance decreases. Both groups had similar changes at 5 years. Epidural steroid provided hope for most patients for temporary 
relief for a duration of 3-6 months with many patients needing repeat injection at variable time. In other studies too Age, gender, profession had no impact on the result of different management. With time, protruded disc regressed, trans ligamentous disc showed greater chances of regression, different studies showed a $60 \%$ volume decrease by 1 year time. Sub ligamentous discs, however, do not regress much (only 17 percent showing regression with time) [14-19].

\section{CONCLUSION}

The present study only gave us a glimpse on the possible treatment modalities and few other factors for lumbar disc disease but a larger study is needed for better insights. Conservative management helped most of the patients while also showing that like other reports males were mostly affected in our study.

\section{REFERENCES}

1. Andersson GB. Epidemiological features of chronic low-back pain. Lancet. 1999; 354(9178):581-585.

2. Amin RM, Andrade NS, Neuman BJ. Lumbar Disc Herniation. Current reviews in musculoskeletal medicine, 2017; 10(4), 507-516.

3. Martin BI, Deyo RA, Mirza SK, Turner JA, Comstock BA, Hollingworth W, Sullivan SD. Expenditures and health status among adults with back and neck problems. JAMA. 2008 Feb 13; 299(6):656-64.

4. Bono CM, Wisneski R, Garfin SR. Lumbar disc herniations. In: Herkowitz HN, Garfin SR, Eismont FJ, Bell GR, Balderston RA, editors. The Spine. 5th ed. Philadelphia, PA: Saunders; 2006.

5. Ala-Kokko L. Genetic risk factors for lumbar disc disease. Ann Med. 2002; 34(1):42-7.

6. Frymoyer LW. Back pain and sciatica. N Eng J Med. 1988; 318:291-300.

7. Hasue M. Pain and the nerve root. An interdisciplinary approach. Spine. 1993; 18:2053-8.

8. Heliövaara M, Impivaara O, Sievers K, Melkas T, Knekt P, Korpi J, Aromaa A. Lumbar disc syndrome in Finland. Journal of Epidemiology \& Community Health. 1987 Sep 1;41(3):251-8.
9. Borenstein D. Epidemiology, etiology, diagnostic evaluation and treatment of low back pain. Curr Opin Rheumatol. 1995;7:141-6.

10. Cherkin DC, Deyo RA, Loeser JD, Bush T, Waddell G. An international comparison of back surgery rates. Spine. 1994; 19: 1201-6.

11. Frymoyer JW. Magnitude of the problem. In: Wiesel SW, Weinstein JN, Herkowitz H, Dvorak J, Bell G, eds. The lumbar spine. Philadelphia, PA: WB Saunders, 1996: 8-16.

12. Perera RS, Dissanayake PH, Senarath U, Wijayaratne LS, Karunanayake AL, Dissanayake VH. Variants of ACAN are associated with severity of lumbar disc herniation in patients with chronic low back pain. PloS one. 2017 Jul 24;12(7):e0181580.

13. Ala-Kokko L. Genetic risk factors for lumbar disc disease. Ann Med. 2002; 34(1):42-7.

14. Schoenfeld AJ, Weiner BK. Treatment of lumbar disc herniation: evidence-based practice. International journal of general medicine. 2010;3:209.

15. Yeung CA. Arizona Institute for Minimally Invasive Spine Care, Phoenix, Arizona. J Clin Neurosci. 2003; 10(2):231-5.

16. Fisher K, Johnson M. Validation of the Oswestry low back pain disability questionnaire, its sensitivity as a measure of change following treatment and its relationship with other aspects of the chronic pain experience. Physiother Theory Pract. 1997; 13, 67-80.

17. Lee JJ, Lee MK, Kim JE, Kim HZ, Park SH, Tae $\mathrm{JH}$, Choi SS. Pain relief scale is more highly correlated with numerical rating scale than with visual analogue scale in chronic pain patients. Pain Physician. 2015 Mar 1;18(2):E195-200.

18. MacCormick AP, Sharma H. Does the severity of pain correlate with severity of functional disability? Factors influencing 'patient reported outcome measures' in spinal patients. SICOT-J. 2018;4.

19. Weber H. Lumbar disc herniation. A controlled, prospective study with ten years of observation. Spine (Phila Pa 1976). 1983 Mar;8(2):131-40. 